\title{
Fundal height growth curve patterns of pregnant women with term low birth weight infants
}

\author{
Jirawan Deeluea ${ }^{1,2}$ \\ Supatra Sirichotiyakul ${ }^{3}$ \\ Sawaek Weerakiet ${ }^{4}$ \\ Suthit Khunpradit ${ }^{5}$ \\ Jayanton Patumanond ${ }^{6}$ \\ 'Clinical Epidemiology Program, \\ Faculty of Medicine, Chiang Mai \\ University, Chiang Mai, Thailand; \\ ${ }^{2}$ Department of Obstetrics and \\ Gynecology Nursing, Faculty of \\ Nursing, Chiang Mai University, \\ Chiang Mai, Thailand; ${ }^{3}$ Department of \\ Obstetrics and Gynecology, Faculty \\ of Medicine, Chiang Mai University, \\ Chiang Mai, Thailand; ${ }^{4}$ Department \\ of Obstetrics and Gynecology, \\ Faculty of Medicine Ramathibodi \\ Hospital, Mahidol University, \\ Bangkok, Thailand; ${ }^{5}$ Department of \\ Obstetrics and Gynecology, Lamphun \\ Hospital, Lamphun, Thailand; ${ }^{6} \mathrm{Clinical}$ \\ Epidemiology Unit and Clinical \\ Research Center, Faculty of Medicine, \\ Thammasat University, Pathum Thani, \\ Thailand
}

This article was published in the following Dove Press journal:

Risk Management and Healthcare Policy

14 July 2014

Number of times this article has been viewed

Purpose: To investigate the patterns of fundal height (FH) growth curve in pregnant women with term low birth weight (LBW) infants compared with the standard FH growth curve for Thai women.

Subjects and methods: A retrospective study was conducted at the four governmental general hospitals in the northern part of Thailand between 2009 and 2011. All data were obtained from antenatal records and labor registry. Serial FH measurements in centimeters of 75 pregnant women with term LBW infants were plotted against the standard FH growth curve for Thai women throughout pregnancy.

Results: Six patterns of the FH growth curve were summarized: pattern I: FH below or around the tenth percentile throughout pregnancy ( $n=17,22.7 \%$ ); pattern II: FH below normal in early pregnancy, caught up with normal, then decelerated or stagnant $(n=19,25.3 \%)$; pattern III: FH normal in early pregnancy, then decelerated or stagnant ( $n=17,22.7 \%)$; pattern IV: FH normal in early pregnancy, decelerated or stagnant, then caught up to normal $(n=6,8.0 \%)$; pattern $\mathrm{V}$ : $\mathrm{FH}$ normal throughout pregnancy except for the last visit ( $\mathrm{n}=6,8.0 \%)$; and pattern VI: FH normal throughout pregnancy $(\mathrm{n}=10,13.3 \%)$.

Conclusion: Patterns I-V may be used to recognize women who are likely to deliver term LBW infants from early pregnancy, during pregnancy, and on the day of admission for labor. Ultrasound evaluation is still recommended in cases with known risk factors that might be undetectable by FH, or in cases where FH measurement may be inaccurate.

Keywords: fetal growth, pregnancy, antenatal care, screening

\section{Introduction}

Term low birth weight (LBW) infants (infants born weighing $<2,500 \mathrm{~g}$, between 37 and 42 completed weeks of gestation) are still prevalent and are among maternal and child health problems in developing countries, including Thailand. A survey in 138 countries of low and middle income in 2010 revealed that there were 10.6 million term LBW infants among 120.5 million live births $(8.8 \%)$, most of them in Asia. ${ }^{1}$ In Thailand the prevalence of LBW infants was $16.0 \%$, among which $7.0 \%$ were preterm LBW and 9.0\% were term $\mathrm{LBW}^{2}$

The majority of term LBW infants are term small for gestational age (SGA) (infants with birth weight below the tenth percentile), ${ }^{1}$ which increases the risk of perinatal morbidity and mortality, including perinatal asphyxia, meconium aspiration syndrome, hypothermia, hypoglycemia, and polycythemia, 3,4 and increased long-term morbidity, including poor mental and psychomotor development, ${ }^{4,5}$ coronary heart disease, type 2 diabetes, and hypertension and stroke in adulthood. ${ }^{6}$ Any screening process to detect

Correspondence: Supatra Sirichotiyaku Department of Obstetrics and Gynecology, Faculty of Medicine, Chiang Mai University, I 10 Inthawaroros road, SriPhum, Chiang Mai 50200, Thailand Tel +6653946433

Fax +6653946II2

Email ssupatra.phd@gmail.com 
pregnant women who are likely to give birth to term LBW infants may lessen these morbidities and mortalities.

Fundal height (FH) measurement is still a simple tool to monitor and screen term LBW infants, especially in settings where ultrasound is not available, as it is a proxy measure of fetal size or fetal weight. ${ }^{7,8}$ Abnormality is suspected when $\mathrm{FH}$ does not match the FH obtained from normal pregnancy for the given gestational age (GA). It is also suspected when the pattern of FH growth reaches the lower boundary of the normal curve, such as -1 standard deviation (SD), -2 SDs, fifth percentile, tenth percentile, and a decelerated pattern or stable pattern that indicates that the fetus may be SGA or may have intrauterine growth restriction ${ }^{8,9}$ leading to term LBW infants.

Previous studies showed that SGA or intrauterine growth restriction could be detected when applying the standard FH growth chart for every antenatal care (ANC) visit. ${ }^{10-12}$ FH growth was dynamic and highly correlated to uterine contents, including the fetus, placenta, and amniotic fluid, but was mostly correlated to fetal size. ${ }^{3}$ Serial FH measurements were therefore used to compare individual FH growth with the standard FH growth chart throughout pregnancy.

The studies on FH measurement in the past mostly focused on developing the "normal" FH growth curve appropriate for the geographical region. ${ }^{13,14}$ No studies focused on the "pattern" of FH growth curve as an indication for abnormal fetal growth. The present study investigates the patterns of FH growth curve in pregnant women with term LBW infants compared with the standard FH growth curve for Thai women. ${ }^{14}$

\section{Subjects and methods Subjects}

Retrospective data were collected of pregnant women with term LBW infants (born weighing $<2,500 \mathrm{~g}$, between 37 and 42 completed weeks of gestation) who attended ANC and delivered in the four governmental general hospitals in the northern part of Thailand between 2009 and 2011. Foreigners, minority groups, women who first visited ANC later than 20 weeks of gestation, unreliable GA, and twin pregnancy were excluded from the cohort inception.

\section{Ascertainment of gestational age}

GA was verified by: 1) first day of last menstrual period (LMP) in cases of regular menstruation, precise recall for LMP, and fundal size well correlated with GA, or LMP-GA was $<1$ week different from ultrasound; and 2) ultrasound was carried out in the first half of pregnancy in case of not recalled LMP, and FH uncorrelated to LMP-GA or $>1$ week different.

\section{Fundal height measurement}

Measurements of $\mathrm{FH}$ in the four settings were based on routine practice care recommended by the Division of Maternal and Child Health, the Ministry of Public Health, Thailand, and recorded in centimeters with nonelastic measurement tape from the upper border of the symphysis pubis to the top of the uterine fundus, or reversed direction. All measurements were taken by experienced nurses or clinicians with at least 2 years of ANC experience, in order to minimize measurement error and bias.

\section{Standard fundal height growth curve for Thai women}

The standard FH growth curve for women in the northern part of Thailand was developed from normal singleton pregnancy based on LMP and/or ultrasound dating reported and published earlier. ${ }^{14}$

In the process of screening, $\mathrm{FH}$ measurement was plotted on the standard FH growth curve displaying the 10th, 50th, and 90th percentile lines for every ANC visit throughout pregnancy.

Criteria for screening were as follows: 1) the fetal size and growth may be "normal" if FH was within the 10th and 90th percentile line and growth rate was a regular increment throughout pregnancy; and 2) the fetus may be smaller than GA or with slow intrauterine growth if FH was below the tenth percentile line or growth rate decelerated or stagnated, whether or not below the tenth percentile.

\section{Data collection and data sources}

Birth weight in grams, first day of LMP, ultrasound report, $\mathrm{FH}$ in centimeters, and general characteristics were extracted from ANC records, labor registry, and related medical records.

\section{Statistical analysis}

The FH measurements obtained from the four settings were standardized to correspond to the subjects used in the development of the standard FH growth curve for Thai women.

The characteristics of the index group (pregnant women with term LBW infants) and the standard group (normal singleton pregnancy used to develop the standard FH growth curve for Thai women) were presented as means, SDs, and 
frequencies and percentages. Comparisons across groups were done with independent $t$-tests or exact probability tests. A $P$-value $<0.05$ was considered statistically significant.

Serial FH measurements of pregnant women with term LBW infants were plotted against the standard FH growth curve for Thai women throughout pregnancy. The patterns of growth were summarized by three researchers in the team. The frequencies observed for each recognized pattern were reported.

\section{Ethical approval}

The study protocol was approved by the Research Ethics Committee, Faculty of Medicine, Chiang Mai University, Chiang Mai, Thailand, and the research ethics committees of the four hospitals.

\section{Results}

A total of 2,351 pregnant women attended ANC and delivered in the four settings during the study period. There were 75 pregnant women with term LBW infants who met the eligible criteria. The average birth weight of the index group was 2,350.8 $\pm 130.5 \mathrm{~g}$. Maternal height, prepregnancy weight, total weight gain, gestational weight gain within the recommendations of the Institute of Medicine, ${ }^{15}$ and GA at birth of the index group were significantly lower than the standard group (Table 1). Settings, maternal age, prepregnancy body mass index (BMI), parity, GA at first antenatal visit, and infant's sex were similar (Table 1).

\section{Patterns of $\mathrm{FH}$ growth curve for pregnant women with term LBW infants}

Serial FH measurements of 75 pregnant women with term LBW infants against the standard FH growth curve for Thai women throughout pregnancy revealed six patterns of the FH growth curve. Examples of the six patterns are shown in Figure 1. The characteristics of the pregnant women for each pattern are shown in Table 2.

- Pattern I $(n=17,22.7 \%)$ : the FHs were around or below the tenth percentile throughout pregnancy (Figure 1A).

- Pattern II ( $n=19,25.3 \%)$ : the FHs were around or below the tenth percentile in early GA and resumed to a normal level afterward, then became decelerated or stagnant until before delivery, at which time they were either below the tenth percentile $(n=16,21.3 \%)$ or above the tenth percentile $(n=3,4.0 \%)$ (Figure 1B).

Table I Characteristics of study subjects

\begin{tabular}{|c|c|c|c|}
\hline Characteristics & $\begin{array}{l}\text { Pregnant women with term } \\
\text { LBW infants (index group) } \\
\text { (n=75; } 530 \text { visits) }\end{array}$ & $\begin{array}{l}\text { Normal singleton pregnancies } \\
\text { (standard group) } \\
\text { ( } \mathrm{n}=\mathrm{I}, 038 ; \mathbf{7 , 5 2 3} \text { visits) }\end{array}$ & P-value \\
\hline \multicolumn{3}{|l|}{ Settings (n, \%) } & \multirow[t]{3}{*}{0.202} \\
\hline Secondary care hospitals & $56(74.7)$ & $696(67.0)$ & \\
\hline Tertiary care hospitals & $19(25.3)$ & $342(33.0)$ & \\
\hline Maternal age $($ year)* & $25.0 \pm 7.6$ & $25.6 \pm 6.2$ & 0.456 \\
\hline Maternal height $(\mathrm{cm})^{*}$ & $153.4 \pm 5.3$ & $|56| \pm 5.6$. & $<0.00$ I \\
\hline Prepregnancy weight $(\mathrm{kg})^{*}$ & $49.3 \pm 7.4$ & $52.6 \pm 9.8$ & $<0.001$ \\
\hline Prepregnancy BMI $\left(\mathrm{kg} / \mathrm{m}^{2}\right)^{*}$ & $21.0 \pm 2.9$ & $21.6 \pm 3.8$ & 0.074 \\
\hline Total weight gain $(\mathrm{kg})^{*}$ & 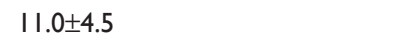 & $13.5 \pm 4.7$ & $<0.001$ \\
\hline \multicolumn{3}{|l|}{ Gestational weight gain $(n, \%)^{c}$} & \multirow[t]{4}{*}{$<0.001$} \\
\hline Less than recommended & $40(53.3)$ & $303(29.2)$ & \\
\hline Within recommended & $28(37.3)$ & $430(41.4)$ & \\
\hline More than recommended & $7(9.4)$ & $305(29.4)$ & \\
\hline \multicolumn{3}{|l|}{ Parity (n, \%) } & \multirow[t]{3}{*}{0.403} \\
\hline Nulliparous & $42(56.0)$ & $523(50.4)$ & \\
\hline Multiparous & $33(44.0)$ & $515(49.6)$ & \\
\hline GA at first antenatal visit (week)* & $12.7 \pm 5.2$ & $13.0 \pm 5.0$ & 0.586 \\
\hline GA at birth (week)* & $38.4 \pm 0.9$ & $39.2 \pm 1.1$ & $<0.00$ I \\
\hline \multicolumn{3}{|l|}{ Infant's sex (n, \%) } & \multirow[t]{3}{*}{0.187} \\
\hline Female & $4 \mid(54.7)$ & $479(46.2)$ & \\
\hline Male & $34(45.3)$ & $559(53.8)$ & \\
\hline Birth weight $(g)^{*}$ & $2,350.8 \pm 130.5$ & $3,120.3 \pm 325.0$ & $<0.001$ \\
\hline \multicolumn{4}{|c|}{ 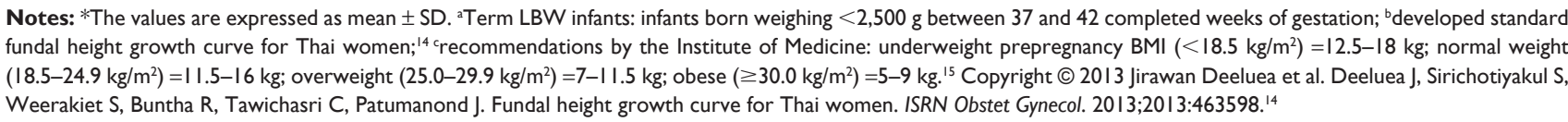 } \\
\hline \multicolumn{4}{|c|}{ Abbreviations: BMI, body mass index; GA, gestational age; LBW, low birth weight; SD, standard deviation. } \\
\hline
\end{tabular}




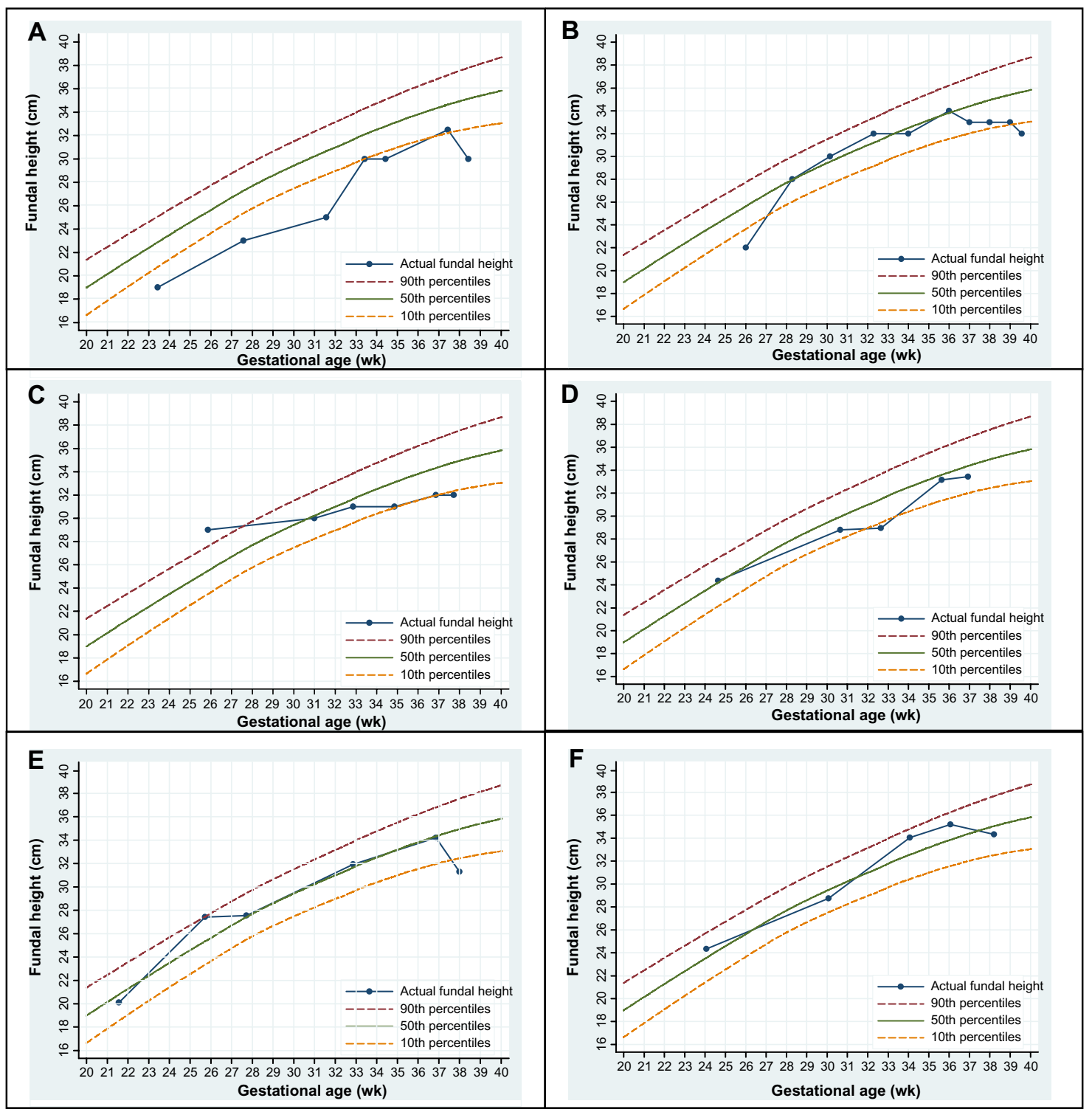

Figure I Example of FH growth curve patterns of six selected pregnant women with term LBW infants against standard FH growth curve for Thai women. Notes: (A) Pattern I: FH below or around the tenth percentile throughout pregnancy. (B) Pattern II: FH below normal in early pregnancy, caught up with normal, then decelerated or stagnant. (C) Pattern III: FH normal in early pregnancy, then decelerated or stagnant. (D) Pattern IV: FH normal in early pregnancy, decelerated or stagnant, then caught up to normal. (E) Pattern V: FH normal throughout pregnancy except for the last visit. (F) Pattern VI: FH normal throughout pregnancy.

Abbreviations: FH, fundal height; LBW, low birth weight; wk, week.

- Pattern III ( $\mathrm{n}=17,22.7 \%)$ : the FHs were between the 50th and 90th percentile in early GA, then became decelerated or stagnant until before delivery, at which time they were either below the tenth percentile ( $\mathrm{n}=15,20.0 \%)$ or above the tenth percentile $(n=2,2.7 \%)$ (Figure 1C).

- Pattern IV ( $\mathrm{n}=6,8.0 \%$ ): the FHs were between the 50th and 90th percentile in early GA, then became decelerated or stagnant until they were either below the tenth percentile $(n=3,4.0 \%)$ or above the tenth percentile $(n=3,4.0 \%)$, but resumed to a normal level afterward (Figure 1D).

- Pattern V ( $n=6,8.0 \%)$ : the FHs were between the 10th and 90th percentile throughout pregnancy, except for a visit before or at delivery, when FH was below the 10th percentile (Figure 1E).

- Pattern VI ( $n=10,13.3 \%)$ : the FHs were between the 10th and 90th percentile lines throughout pregnancy (Figure 1F).

\section{Discussion}

The standard FH growth curve for Thai women with 10th, 50th, and 90th percentile lines was supposed to be a simple tool to monitor fetal growth and to screen for suspected abnormal intrauterine growth. Small fetuses or fetuses with a slow intrauterine growth rate should be recognized by a 
Table 2 Characteristics of pregnant women for six patterns of fundal height growth curve $(n=75)$

\begin{tabular}{|c|c|c|c|c|c|c|}
\hline \multirow[t]{2}{*}{ Characteristics } & $\begin{array}{l}\text { Pattern I } \\
(n=17)\end{array}$ & $\begin{array}{l}\text { Pattern II } \\
(n=19)\end{array}$ & $\begin{array}{l}\text { Pattern III } \\
(n=17)\end{array}$ & $\begin{array}{l}\text { Pattern IV } \\
(n=6)\end{array}$ & $\begin{array}{l}\text { Pattern V } \\
(n=6)\end{array}$ & $\begin{array}{l}\text { Pattern VI } \\
(n=10)\end{array}$ \\
\hline & Mean \pm SD & Mean \pm SD & Mean \pm SD & Mean \pm SD & Mean \pm SD & Mean \pm SD \\
\hline Age (year) & $20.1 \pm 4.6$ & $27.2 \pm 7.8$ & $26.1 \pm 6.7$ & $23.8 \pm 10.5$ & $28.0 \pm 8.4$ & $26.0 \pm 8.3$ \\
\hline Height (cm) & $153.9 \pm 5.7$ & $154.3 \pm 3.6$ & $154.5 \pm 6.3$ & $153.1 \pm 3.0$ & $153.4 \pm 2.9$ & $149.3 \pm 6.5$ \\
\hline Prepregnancy weight (kg) & $46.3 \pm 7.1$ & $47.6 \pm 5.3$ & $54.6 \pm 9.0$ & $49.7 \pm 5.7$ & $49.3 \pm 8.2$ & $48.7 \pm 6.0$ \\
\hline Prepregnancy BMI (kg/m²) & $19.5 \pm 2.9$ & $20.0 \pm 2.1$ & $22.9 \pm 3.2$ & $21.2 \pm 2.1$ & $20.9 \pm 2.9$ & $21.9 \pm 2.5$ \\
\hline Total weight gain (kg) & $8.9 \pm 3.2$ & $10.7 \pm 2.9$ & $10.6 \pm 5.0$ & $12.8 \pm 7.2$ & 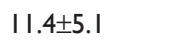 & $14.6 \pm 4.4$ \\
\hline Low gestational WGa $(n, \%)$ & $13(76.5)$ & $12(63.2)$ & $7(4 \mid .2)$ & $3(50.0)$ & $3(50.0)$ & $2(20.0)$ \\
\hline Nulliparous (n, \%) & $12(70.6)$ & $7(36.8)$ & $10(58.8)$ & $3(50.0)$ & $5(83.3)$ & $5(50.0)$ \\
\hline GA at birth (wk) & $38.2 \pm 0.7$ & $38.3 \pm 0.8$ & $38.7 \pm 0.9$ & $38.8 \pm 1.2$ & $38.0 \pm 0.9$ & $38.3 \pm 0.9$ \\
\hline Female infant (n, \%) & $9(52.9)$ & II (57.9) & $9(52.9)$ & $3(50.0)$ & $4(66.7)$ & $5(50.0)$ \\
\hline Birth weight (g) & $2,284.4 \pm 156.5$ & $2,386.0 \pm 112.6$ & $2,376.2 \pm 108.3$ & $2,338.3 \pm 156.9$ & $2,374.2 \pm 121.4$ & $2,347.0 \pm 125.3$ \\
\hline \multicolumn{7}{|l|}{ Medical complications (n, \%) } \\
\hline Chronic hypertension & N/A & $\mathrm{N} / \mathrm{A}$ & $\mathrm{N} / \mathrm{A}$ & N/A & $\mathrm{N} / \mathrm{A}$ & I (I0.0) \\
\hline Pregestational DM & N/A & $\mathrm{N} / \mathrm{A}$ & I (5.9) & N/A & $\mathrm{N} / \mathrm{A}$ & $\mathrm{N} / \mathrm{A}$ \\
\hline Thalassemia disease & I (5.9) & I (5.3) & $\mathrm{N} / \mathrm{A}$ & N/A & N/A & $N / A$ \\
\hline Asthma & N/A & I (5.3) & $\mathrm{N} / \mathrm{A}$ & $N / A$ & $\mathrm{~N} / \mathrm{A}$ & $\mathrm{N} / \mathrm{A}$ \\
\hline \multicolumn{7}{|l|}{ Obstetric complications (n, \%) } \\
\hline Hyperemesis gravidarum & $\mathrm{N} / \mathrm{A}$ & $\mathrm{N} / \mathrm{A}$ & I (5.9) & $N / A$ & $\mathrm{~N} / \mathrm{A}$ & $\mathrm{N} / \mathrm{A}$ \\
\hline Gestational hypertension & $\mathrm{N} / \mathrm{A}$ & $\mathrm{N} / \mathrm{A}$ & $\mathrm{N} / \mathrm{A}$ & N/A & $\mathrm{N} / \mathrm{A}$ & I (I0.0) \\
\hline Anemia during pregnancy & $2(11.8)$ & $\mathrm{N} / \mathrm{A}$ & I (5.9) & I (I6.7) & N/A & N/A \\
\hline Oligohydramnios & I (5.9) & $\mathrm{I}(5.3)$ & I (5.9) & $\mathrm{N} / \mathrm{A}$ & $\mathrm{N} / \mathrm{A}$ & $\mathrm{N} / \mathrm{A}$ \\
\hline IUGR & $7(4 \mid .2)$ & I (5.3) & $2(11.8)$ & N/A & $\mathrm{N} / \mathrm{A}$ & I (I0.0) \\
\hline
\end{tabular}

Note: a Gestational weight gain was lower than the recommendations by the Institute of Medicine. ${ }^{15}$

Abbreviations: BMI, body mass index; DM, diabetes mellitus; GA, gestational age; IUGR, intrauterine growth restriction; SD, standard deviation; WG, weight gain; wk, week.

deviation from FH growth of the norms, as shown by both the pattern of growth and the timing at which the abnormality was detected.

The findings suggested six different patterns of FH growth curve observed in pregnant women with term LBW infants. Each pattern may have different or similar explanations as follows.

\section{Pattern I}

The fetus is likely to be small throughout pregnancy. This may reflect genetic and constitutional influences such as mothers with a small body frame and mothers who were SGA or who had delivered LBW infants, resulting in a "constitutionally" or "natural" small infant with otherwise normal growth. ${ }^{16,17}$ It may also reflect risk factors for term LBW infants from the beginning of pregnancy, such as nulliparous, teenage, low prepregnancy weight, low BMI, or thalassemia disease, combined with low gestational weight gain, anemia during pregnancy, or an abnormal placenta that led to insufficient nutrients and oxygen supply to the fetus and resulting in intrauterine growth restriction. ${ }^{17-19}$ Pregnant women in this pattern had lower age, prepregnancy weight, prepregnancy BMI, and gestational weight gain than those in patterns II-VI (Table 2).

\section{Pattern II}

The fetus is likely to be small in early pregnancy, which may be due to risk factors for term LBW infants such as a small mother, nulliparous, low BMI, maternal malnutrition, or diseases leading to hypoxemia such as asthma or thalassemia disease. Nutrient and oxygen supply to the fetus may be improved from better nutrition ${ }^{20}$ or underlying controllable conditions, ${ }^{9}$ resulting in resumption to normal levels. Nutrients, especially glucose, may be insufficient in the last trimester, ${ }^{3}$ and low gestational weight gain, psychosocial stress, or abnormal function of the placenta ${ }^{17,21}$ may lead to decelerated growth observed in late pregnancy.

\section{Pattern III}

The fetus is likely to be normal in early pregnancy. The growth rate may be decelerated from late causes for term LBW infants such as vascular diseases, anemia during pregnancy, partial placental separation, intervillous or spiral artery thrombosis, or placental infarcts leading to uteroplacental insufficiency or hypoxemia, ${ }^{19,22}$ combined with poor maternal nutrition, especially in the third trimester, or low gestational weight gain leading to fetal undernutrition. ${ }^{17,18}$ 


\section{Pattern IV}

The fetus is likely to be normal in early pregnancy. Late causes for term LBW infants decelerated the growth but are corrected or received intervention, causing resumption of the growth rate, but are insufficient to catch up with the norms. Other causes for FH larger than the actual size of the fetus in late pregnancy may be observed where there is excessive volume of amniotic fluid, abnormal fetal position, or abnormal pelvis. ${ }^{23}$

\section{Pattern V}

The fetus is likely to be normal throughout pregnancy. Uteroplacental insufficiency may be encountered near term. ${ }^{24}$ As fetal weight gain beyond 34 weeks should be $30-35 \mathrm{~g} /$ day or $210-245 \mathrm{~g} /$ week, ${ }^{3}$ the rate below this may result in term $\mathrm{BW}<2,500 \mathrm{~g}$.

\section{Pattern VI}

As FH is only a surrogate measure for fetal size, it does not reflect just the fetal size but may be influenced by the amount of amniotic fluid, fetal position, body shape, and types of pelvis. ${ }^{23}$ Furthermore, a standard FH growth curve derived from all pregnant women may not be appropriate for women with low or high BMI, ${ }^{25}$ causing false classification.

From the six patterns proposed, there were four patterns (patterns I-IV) that may be used as guidelines to screen for term LBW infants from early pregnancy $(78.7 \%)$, and one pattern (pattern V) that may be used to detect the condition only before or at delivery $(8.0 \%)$. The other pattern (pattern VI) failed to detect such condition (13.3\%).

In pattern VI, where the FH growth curve did not indicate any abnormalities, other factors contributive to a falsely large FH should be explored, such as women with BMI $>35 \mathrm{~kg} / \mathrm{m}^{2}$, which may lead to inaccurate measurement, large fibroids, or polyhydramnios. In these cases, other investigations may be required, such as serial ultrasound measurements, uterine artery Doppler, or umbilical artery Doppler. ${ }^{9,26}$ Furthermore, applying an FH growth curve that is more specific to individuals may be more appropriate in underweight or overweight and obese pregnant women. ${ }^{25}$

The patterns of the FH growth curve in pregnant women with term LBW infants plotted against the standard FH growth curve for Thai women may reflect the size and growth of the fetus at different stages of pregnancy. It might be used as a guideline or a simple tool to monitor and screen for term LBW infants, from early pregnancy. Detected cases need intervention to reduce complications that may arise from term LBW infants.
Although the present study may be the first to report the patterns of the FH growth curve in pregnant women with term LBW infants, it was conducted only in women who attended ANC in the four governmental general hospitals in the northern part of Thailand and with a limited number of subjects, as most of the pregnant women with term LBW infants were excluded due to late ANC. The effectiveness and benefit of using this approach in the screening for term LBW infants should be verified by future studies before it is adopted into routine clinical practice.

\section{Conclusion}

The patterns of FH growth curves observed among pregnant women with term LBW infants may be used to identify women who are likely to deliver term LBW infants from early pregnancy, during pregnancy, and on the day of admission for labor. Such screening may detect future term LBW infants in $80 \%$. An intervention in screening-detected cases may reduce the incidence of, or lessen the complications in, fetuses $<2,500 \mathrm{~g}$. Ultrasound evaluation is still recommended in cases with risk factors that cannot be detected by $\mathrm{FH}$ measurements, or in cases where FH measurement may be inaccurate.

\section{Acknowledgments}

The authors would like to thank the authorities of Nakornping, Lampang, Lamphun, and Phayao Hospitals for their permission and support in data retrieval; the Faculty of Medicine, Chiang Mai University for the study grant; and Associate Professor Dr Sirianong Namwongprom, Director of the Clinical Epidemiology Program, Faculty of Medicine, Chiang Mai University for her review and valuable suggestions.

\section{Disclosure}

The authors declare no conflicts of interest.

\section{References}

1. Lee ACC, Katz J, Blencowe H, et al. National and regional estimates of term and preterm babies born small for gestational age in 138 low-income and middle-income countries in 2010. Lancet Glob Health. 2013;1(1): e26-e36.

2. Barros FC, Barros AJ, Villar J, Matijasevich A, Domingues MR, Victora CG. How many low birthweight babies in low- and middle-income countries are preterm? Rev Saude Publica. 2011;45(3):607-616.

3. Cunningham FG, Leveno KJ, Bloom, SL, Hauth JC, Rouse DJ, Spong CY, editors. Williams Obstetrics. 23rd ed. New York: McGrawHill; 2010:842-858.

4. Doctor BA, O'Riordan MA, Kirchner HL, Shah D, Hack M. Perinatal correlates and neonatal outcomes of small for gestational age infants born at term gestation. Am J Obstet Gynecol. 2001;185(3): $652-659$. 
5. Figueras F, Oros D, Cruz-Martinez R, et al. Neurobehavior in term, small-for-gestational age infants with normal placental function. Pediatrics. 2009;124(5):e934-e941.

6. Barker DJ. The developmental origins of chronic adult disease. Acta Paediatr Suppl. 2004;93(446):26-33.

7. Mongelli M, Gardosi J. Estimation of fetal weight by symphysis-fundus height measurement. Int J Gynaecol Obstet. 2004;85(1):50-51.

8. Morse K, Williams A, Gardosi J. Fetal growth screening by fundal height measurement. Best Pract Res Clin Obstet Gynaecol. 2009;23(6):809-818.

9. Royal College of Obstetricians and Gynaecologists. Green-Top Guideline No 31: The Investigation and Management of the Small-for-Gestational Age Fetus. 2nd ed. London, UK: Royal College of Obstetricians and Gynaecologists; 2013.

10. Gardosi J, Francis A. Controlled trial of fundal height measurement plotted on customised antenatal growth charts. Br J Obstet Gynaecol. 1999;106(4):309-317.

11. Wright J, Morse K, Kady S, Francis A. Audit of fundal height measurement plotted on customised growth charts. MIDIRS Midwifery Dig. 2006;16:341-345.

12. Roex A, Nikpoor P, van Eerd E, Hodyl N, Dekker G. Serial plotting on customised fundal height charts results in doubling of the antenatal detection of small for gestational age fetuses in nulliparous women. Aust N Z J Obstet Gynaecol. 2012;52(1):78-82.

13. Freire DM, Cecatti JG, Paiva CS. Symphysis-fundal height curve in the diagnosis of fetal growth deviations. Rev Saude Publica. 2010;44(6): 1031-1038.

14. Deeluea J, Sirichotiyakul S, Weerakiet S, Buntha R, Tawichasri C, Patumanond J. Fundal height growth curve for Thai women. ISRN Obstet Gynecol. 2013;2013:463598.

15. Institute of Medicine. Weight Gain During Pregnancy: Reexamining the Guidelines. Washington, DC: The National Academies Press; 2009.
16. Dunger DB, Petry CJ, Ong KK. Genetics of size at birth. Diabetes Care. 2007;30 Suppl 2:S150-S155.

17. Valero De Bernabe J, Soriano T, Albaladejo R, et al. Risk factors for low birth weight: a review. Eur J Obstet Gynecol Reprod Biol. 2004;116(1):3-15.

18. McCowan L, Horgan RP. Risk factors for small for gestational age infants. Best Pract Res Clin Obstet Gynaecol. 2009;23(6):779-793.

19. Sheridan $C$. Intrauterine growth restriction: diagnosis and management. Aust Fam Physician. 2005;34(9):717-723.

20. Roberfroid D, Huybregts L, Lanou H, et al. Prenatal micronutrient supplements cumulatively increase fetal growth. J Nutr. 2012;142(3): 548-554.

21. Mayer C, Joseph KS. Fetal growth: a review of terms, concepts and issues relevant to obstetrics. Ultrasound Obstet Gynecol. 2013;41(2):136-145.

22. Kleebkaow P, Limdumrongchit W, Ratanasiri T, Komwilaisak R, Seejorn K. Prevalence of placental pathology in low birthweight infants. J Med Assoc Thai. 2006;89(5):594-599.

23. Varney H, Kriebs JM, Gegor CL. Varney's Midwifery. 4th ed. Sudbury, MA: Jones and Bartlett; 2004

24. Cetin I, Alvino G. Intrauterine growth restriction: implications for placental metabolism and transport: a review. Placenta. 2009; 30 Suppl A:S77-S82.

25. Deeluea J, Sirichotiyakul S, Weerakiet S, Arora R, Patumanond J. Fundal height growth curve for underweight and overweight and obese pregnant women in Thai population. ISRN Obstet Gynecol. 2013;2013:657692.

26. Figueras F, Gardosi J. Intrauterine growth restriction: new concepts in antenatal surveillance, diagnosis, and management. Am J Obstet Gynecol. 2011;204(4):288-300.
Risk Management and Healthcare Policy

\section{Publish your work in this journal}

Risk Management and Healthcare Policy is an international, peerreviewed, open access journal focusing on all aspects of public health, policy, and preventative measures to promote good health and improve morbidity and mortality in the population. The journal welcomes submit ted papers covering original research, basic science, clinical \& epidemio-

\section{Dovepress}

logical studies, reviews and evaluations, guidelines, expert opinion and commentary, case reports and extended reports. The manuscript management system is completely online and includes a very quick and fair peerreview system, which is all easy to use. Visit http://www.dovepress.com/ testimonials.php to read real quotes from published authors. 